management of extremity injuries in such conditions is to achieve the rapid transportability of the casualies.

Our new methodology is based upon the combined use of a disposable and a sophisticated fixation device applied to the commonly used pin system. For initial management, the cheap, single-use device is applied, and after transportation, it can be changed for the better developed devices. The use of our single-use fixators demonstrated that they functioned with favourable results even when used in peacetime surgery and that they are cost effective. None of the presently existing so-called war-fixator systems meet the requirements for the budgetary and logistic aspects of the management of mass casualties. In the third world and in underdeveloped countries, there are no funds either in war or in peacetime to treat such terrible situations in professionally correct way. The costs of surgical management are sometimes so high that they cause socio-economic dilemmas even in developed countries. The Manuflex system was developed by the author's own invention and seems to help answer this difficult question.

043.

\section{Hospital Trauma Surgery in Mass Casualty Situations: A New Approach}

\section{A. Hirshberg, $M D, A$. Shacar, $M D, R$. Walden, $M D$}

The Sheba Medical Center Tel Hashomer, and Sackler

Medical School, Tel Aviv University, Tel Aviv, Israel

Disaster planning relates mainly to the organizational aspects of medical care required in mass casualty situations. The principles of patient care once the casualties have reached the hospital are not well-defined. It is implied that the in-hospital surgical management of individual patients in a disaster scenario is based on accepted standards of care defined for civilian trauma.

Our team developed precise clinical guidelines for the surgical care of the wounded in a mass casualty situation. This is based on adaptation of principles of military field surgery to the civilian hospital set-up. During the actual intake of causalities, the prime consideration is the correct distribution and conservation of critical hospital resources by providing minimal acceptable care (rather than optimal care) to the maximal number of salvageable patients. The second (definitive) phase takes place when casualties no longer are arriving at the hospital. Then, optimal care is provided to all patients in a priorityoriented graded fashion.

Guidelines for minimal acceptable care include immediate surgery only for patients who are hemodynamically unstable following truncal injuries, and for patients who neurologically unstable following head injuries that are salvageable. Penetrating abdominal trauma in stable patients are treated non-operatively, and chest trauma is managed by empirical tube thoracostomy without a chest X-ray. Suspected extremity fractures are immobilized without $X$-ray. Agonal patients are not resuscitated. The great majority of patients are admitted temporarily to the hospital wards without imaging or laboratory studies, and await further work-up and surgery during the second phase.

This new strategy provides a practical framework for the optimal utilization of limited hospital resources in disaster situations.

011.

\section{Bellows or Bag? A Test of 10 Ventilators}

K. Kotter, ${ }^{l}$ W. Maleck, ${ }^{2}$ J. Herchet, ${ }^{3}$ S. Altmannsberger, ${ }^{4}$

G. Petroianu, ${ }^{4}$ E. Frimberger ${ }^{5}$

lDepartment of Head Trauma Reha-Krhs. D-76307 Karlsbad

2Klinikum Ludwigshafen

${ }^{3}$ St. John's Ambulance, Mannheim

${ }^{4}$ Klinikum Mannheim

5Internal Medicine II TU Munich

Objective: Ventilation in CPR usually is started with bag-valvemask. The American Heart Association recommendations (0.8-1.2 liters in 1.5-2 seconds) are difficult to fulfill.1,2,3 Do bellows ventilators have advantages in this circumstance? ${ }^{4,5}$

Materials: One ventilation bag (Ambu Mark 3: AM); 6 ventilation balls (Ambu Silicon: AS; Laerdal: LA; Drager 2000: D2; Hope: HO; Mercury: ME; Weinmann: WE), and 3 bellows ventilators (Kendall Cardiovent: KE; Drager Resusitator 63: DR; Tagg Breathsaver: BR).

Methods: Twelve paramedics performed mask ventilation on a Laerdal Recording Anne lying on the floor (FATStechnique ${ }^{2,3}$ ) and in a bed, trying to achieve 0.8-1.2 liter tidal volume. The graphical strips were analyzed. The probands judged the performance on a 6 -point scale ( $1=$ very good, $6=$ insufficient).

Results:

\begin{tabular}{lcccccc} 
& \multicolumn{3}{c}{ Tidal volume (liters) } & \multicolumn{3}{c}{ Max. TV Performance } \\
& \multicolumn{4}{c}{ Percent Achieving } \\
& $<0.5$ & $0.5-0.75$ & $0.8-1.2$ & $>1.2$ & (Liter) & (Mean) \\
AM & 1 & 25 & 72 & 2 & 1.3 & 1.7 \\
AS & 1 & 8 & 71 & 20 & 1.4 & 2.8 \\
LA & 0 & 16 & 67 & 17 & 1.5 & 2.5 \\
D2 & 2 & 17 & 68 & 13 & 1.5 & 3.4 \\
HO & 1 & 21 & 68 & 10 & 1.45 & 4.6 \\
ME & 2 & 19 & 60 & 19 & 1.5 & 3.4 \\
WE & 20 & 43 & 37 & 0 & 1.1 & 4.6 \\
KE & 0 & 12 & 87 & 1 & 1.25 & 1.8 \\
DR & 2 & 22 & 76 & 0 & 1.15 & 3.4 \\
BR & 7 & 32 & 61 & 0 & 1.15 & 4.9
\end{tabular}

Conclusions: The bellows of Kendall (prototype) and Drager (historical) allowed an exact ventilation comparable to the best conventional ventilator (Ambu Mark 3). The balls (except Weinmann) showed a tendency to high volumes (danger of gastric inflation). Ambu Mark 3 and Kendall Cardiovent were judged best in performance.
References
1. AHA: JAMA 1992;268:2171.
2. Barnes: Respir Care 1992;37:673.
3. Cummins: Ann Emerg Med 1986;15:1187.
4. Frimberger, 2nd PECEMS 1994; A21.
5. Kreiselman: Anesthesiology 1943;4:608. 